\title{
Prediksi Trend Pergerakan Harga Saham dengan Hidden Markov Model (HMM) dan Support Vector Machine (SVM)
}

\author{
Firdaniza $^{1}$, Jondri ${ }^{2}$ \\ 1)Prodi Matematika,Fakultas MIPA, UniversitasPadjadjaran \\ Jl. Raya Bandung Sumedang KM 21 Jatinangor Sumedang 45363 \\ Email: firdaniza.unpad@gmail.com \\ 2) Prodi Teknik Informatika Universitas Telkom \\ Jl. Telekomunikasi, TerusanBuahBatu Bandung \\ Email: jdn@ittelkom...ac.id
}

\begin{abstract}
ABSTRAK
Prediksi trend pergerakan harga saham sangatlah dibutuhkan untuk meningkatkan potensi keuntungan sekaligus mengurang kemungkinan rugi. Berbagai metode telah digunakan untuk memprediksi trend pergerakan harga saham. Pada paper ini, dibahas metode Hidden Markov Model (HMM) dan Support Vector Machine (SVM) sebagai alat untuk memprediksi trend naik turunnya harga close Indeks LQ45. Akurasi prediksi dengan HMM sebesar 50,98\%, sementara dengan SVM sebesar 55,56\%.
\end{abstract}

Kata kunci: Hidden Markov Model, Support Vector Machine, Harga Saham.

\section{ABSTRACT}

Predicted trend of stock price movements are needed to increase the profit potential while reducing the possibility of loss. Various methods have been used to predict the trend of stock price movements. In this paper, we use Hidden Markov Models (HMM) and Support Vector Machine (SVM) as a tool to predict trend of stock price fluctuations of the close price of LQ45 index. With HMM prediction accuracy of 50.98\%, while the SVM was $55.56 \%$

Keywords: Hidden Markov Model, Support Vector Machine, stock price.

\section{Pendahuluan}

Saham adalah satuan nilai dalam berbagai instrument finansial yang mengacu pada bagian kepemilikan sebuah perusahaan. Dengan menerbitkan saham, memungkinkan perusahaanperusahaan yang membutuhkan dana jangka panjang untuk 'menjual' dengan imbalan uang tunai untuk modal bisnisnya. Harga saham dapat dilihat sewaktu-waktu di bursa efek kapanpun orang menginginkan. Investor akan memperhatikan dinamika harga saham setiap saat untuk memperkirakan kapan dia harus menjual atau membeli saham agar dia memperoleh keuntungan. Indeks LQ45 merupakan indeks harga saham dari 45 saham pilihan dengan tingkat likuiditas dan kapitalisasi pasar tertinggi. Indeks LQ45 bertujuan sebagai pelengkap IHSG dan khususnya menyediakan sarana yang objektif dan terpercaya bagi analis keuangan, manajer investasi, investor, dan pemerhati pasar modal lainnya dalam memonitor pergerakan harga dari saham-saham yang aktif di perdagangkan. Untuk dapat memprediksi trend harga saham, investor harus mempunyai teknik analisis yang kuat sebagai dasar pengambilan keputusan. Berbagai metoda sudah banyak digunakan.

Untuk memprediksi harga saham atau trend harga saham dapat digunakan analisis fundamental dan analisis teknikal. Analisis fundamental menggunakan data tentang laporan keuangan perusahaan, manajemen perusahaan, kondisi makro ekonomi, serta kondisi mikro ekonomi terkait dengan bidang usaha perusahaan yang akan diprediksi harga sahamnya. Analisis teknikal menggunakan data historis harga saham suatu perusahaan.

Baresa [1] menganalisa pengaruh makro dan mikro ekonomi pada bisnis perusahaan untuk memprediksi harga saham perusahaan tersebut di masa mendatang. Venkates [6] menggunakan data tentang kebijakan keuangan, keuntungan, dan efisiensi perusahaan farmasi, keuangan, dan teknologi informasi di bursa saham India untuk memprediksi return dari saham perusahaan tersebut, dimana return ini akan menjadi faktor penyebab naik atau turunnya harga saham suatu perusahaan. 
Analisis teknikal yang biasa digunakan oleh para pialang saham adalah moving average, karena metodanya paling sederhana. Harga saham besok diramal dari harga rata-rata harga saham harihari sebelumnya. Hasan-Nath [3], menggunakan Hidden Markov Model (HMM) untuk memprediksi harga saham. Data yang digunakan adalah harga close.

Pada paper ini dikaji penerapan HMM untuk memprediksi trend harga saham dengan menggunakan harga close. Disamping itu, supaya dapat menggunakan data histori lebih banyak yang diformulasikan dalam berbagai macam teknikal indikator, akan dikaji metoda Support Vector Machine (SVM) untuk memprediksi trend harga saham dengan menggunakan beberapa teknikal indikator sebagai atribut.

\section{Metode Penelitian}

Untuk kasus data harga saham, state tidak dapat diamati secara langsung, tetapi dapat di diobservasi melalui himpunan pengamatan lain, dalam hal ini data harga saham berbentuk open, high, low, close. Dalam metoda ini, satu set data masa lalu dianalisis dan dilakukan training HMM yang selanjutnya digunakan untuk memprediksi trend harga saham hari yang akan datang. Pada paper ini akan digunakan Hidden Markov Model (HMM) dan Support Vector Machine (SVM) dalam memprediksi trend pergerakan harga indeks LQ45. Nilai close dari indeks LQ45 diklasifikasi ke dalam "naik" dan "turun". Sebagian data dijadikan data training dan sebagian lainnya dijadikan data testing. Dengan HMM dan SVM akan dilihat akurasinya dalam memprediksi trend harga saham.

\section{Hasil dan Pembahasan}

\subsection{Hidden Markov Model (HMM)}

Hidden Markov Model (HMM) adalah rantai Markov dengan statenya tidak dapat diamati secara langsung, tetapi hanya dapat diobservasi melalui himpunan pengamatan lain, Elemen-elemen HMM antara lain: Rabiner [5]

1. $X_{t}$ yaitu state pada waktu $t$.

2. $X=\left\{X_{1}, X_{2}, \ldots, X_{N}\right\}$ yaitu ruang state dengan $N$ adalah jumlah state.

3. $O_{t}$ yaitu observasi pada waktu $t$.

4. $V=\left\{v_{1}, v_{2}, \ldots, v_{M}\right\}$ yaitu ruang observasi dengan $M$ adalah jumlah observasi.

5. $\Pi_{i}$ yaitu distribusi state awal.

6. $\mathbf{A}=\left[a_{i j}\right]$, yaitu matriks peluang transisi dari state $i$ ke $j$.

7. $\mathbf{B}=\left[b_{j m}\right]$, yaitu matriks peluang observasi $v_{m}$ pada state $j$, dimana:

8. $b_{j m}=b_{j}\left(O_{t}\right)=P\left(O_{t}=v_{m} \mid X_{t}=s_{j}\right), 1 \leq j \leq N$ dan $1 \leq m \leq M$

9. $H M M$ dinotasikan dengan $\lambda=(\mathbf{A}, \mathbf{B}, \mathbf{\Pi})$

Prediksi trend harga saham dengan HMM dilakukan dengan menyelesaikan 3 masalah utama HMM, yakni :
a. Evaluation problem
b. Decoding problem
c. Learning problem.

Pada evaluation problem, dihitung $P(O \mid \lambda)$ dengan prosedur forward, artinya dicari peluang barisan observasi jika diberikan parameter $\lambda=(\mathbf{A}, \mathbf{B}, \boldsymbol{\pi})$. Dalam hal ini digunakan variabel forward,

$$
\alpha_{t}(i)=P\left(O_{1}, O_{2}, \ldots, O_{t}, X_{t}=S_{i} \mid \lambda\right.
$$

Selanjutnya, pada decoding problem, ditentukan barisan state optimal $X=\left\{X_{1}, X_{2}, \ldots, X_{N}\right\}$ jika diberikan parameter $\lambda=(\mathbf{A}, \mathbf{B}, \boldsymbol{\pi})$ dan barisan observasi O. Decoding problem diselesaikan dengan memanfaatkan variable forward dan backward, yakni $\gamma_{t}(i)=P\left(X_{t}=s_{i} \mid O, \lambda\right)$.

Kemudian learning problem, menentukan parameter HMM $\lambda=(\mathbf{A}, \mathbf{B}, \boldsymbol{\pi})$ agar diperoleh $P(O \mid \lambda)$ maksimum. 
Metode yang digunakan dalam learning problem ini adalah algoritma Baum-Welch. Pada algoritma ini digunakan variabel forward, backward, $\gamma_{t}(i)$, dan $\xi_{t}(i, j)$.

$$
\begin{gathered}
\xi_{t}(i, j)=P\left(X_{t}=s_{i}, X_{t+1}=s_{j} \mid O, \lambda\right) \\
\gamma_{t}(i)=\sum_{j=1}^{N} \xi_{t}(i, j)
\end{gathered}
$$

$P(O \mid \lambda)$ akan maksimum jika $\sum_{t=1}^{T-1} \gamma_{t}(i) \neq 0$.

Langkah-langkah prediksi trend harga close indeks LQ45 dengan menggunakan HMM adalah sebagai berikut:

1. Klasifikasikan nilai close harga saham LQ45 periode 4 Maret 2013 sampai 27 Januari 2014 menjadi "naik" dan "turun"dengan mencari selisih harga close hari ini dengan harga close hari kemarin. Diperoleh data sebanyak 210 data, dibagi menjadi data training sebanyak 160 buah dan 50 sebagai data testing.

2. Gunakan data training uuntuk memperoleh matriks peluang transisi A dan matriks peluang emisi B dengan Algoritma Baum-Welch.

Diperoleh :

$$
A=\left[\begin{array}{cc}
0,6007 & 0,3993 \\
0 & 1
\end{array}\right] \quad B=\left[\begin{array}{cc}
0,5567 & 0,4433 \\
0,4567 & 0,5433
\end{array}\right]
$$

3. Dengan HMM decoding, hitung peluang observasi $O=\left\{O_{d-9}, O_{d-8}, \ldots, O_{d}, O_{d+1}\right\}$ dengan $O_{d+1}$ adalah kemungkinan nilai observasi (naik/turun). Artinya, dari 10 nilai close sebelumnya, dihitung peluang hari ke 11 akan "naik" atau "turun".

4. Harga saham hari ke-11 diprediksi "naik" jika peluang harga "naik" lebih dari peluang harga "turun", sebaliknya, harga saham hari ke-11 diprediksi "turun" jika peluang harga "turun " lebih dari peluang harga "naik"

5. Bandingkan hasil prediksi dengan data sebenarnya, diperoleh akurasi 50,98\%.

\subsection{Support Vector Machine (SVM)}

Support Vector Machine (SVM) adalah metode yang digunakan untuk mengklasifikasikan data, diterapkan pada banyak permasalah nyata seperti pada data mining, machine learning dan pengenalan pola, Cristianini [2]. Prinsip kerja dari metoda SVM adalah menentukan model classifier (biasanya berupa hyperplane) yang memisahkan data dari dua kelas yang berbeda. Koefisienkoefisien dari hyperplane classifier dipilih sehingga jarak hyperplane ke titik-titik terdekat dari kedua kelas paling jauh.

Diberikan himpunan data $\left(x_{1}, y_{1}\right),\left(x_{2}, y_{2}\right), \ldots,\left(x_{N}, y_{N}\right) \in R^{n} x R$ yang dapat dipisah secara linear ke dalam kelas A (dinotasikan dengan indeks 1) dan kelas B (dinotasikan dengan indeks -1).Dalam hal ini $x_{i}$ menyatakan atribut.

Hyperplane terbaik yang memisahkan kedua data tersebut dapat diperoleh berupa hyperlane

$$
\boldsymbol{w}^{T} \boldsymbol{x}+\boldsymbol{b}=\boldsymbol{0}
$$

Sehingga jarak hyperplane ke titik terdekat dari kedua kelas bernilai maksimal (Ilustrasi dalam dua dimensi dapat dilihat pada Gambar 1). 


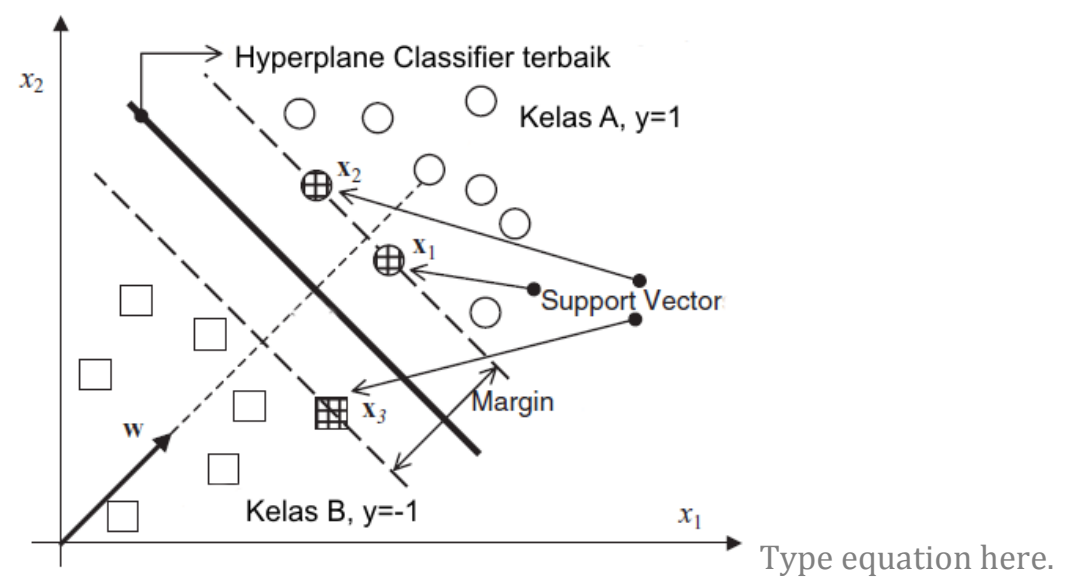

Gambar 1. Ilustrasi hyperplane classifier terbaik [2]

Agar hyperplane (1) memisahkan data ke dalam kedua kelas, maka dapat dipilih vektor $\mathbf{w}$ dan $\mathbf{b}$ sehingga

$$
\begin{aligned}
& \boldsymbol{w}^{T} \boldsymbol{x}_{i}+\boldsymbol{b}>\boldsymbol{0}, \quad \text { jika } \boldsymbol{x}_{i} \in A \\
& \text { dan } \\
& \boldsymbol{w}^{T} \boldsymbol{x}_{i}+\boldsymbol{b}<\boldsymbol{0}, \quad \text { jika } \boldsymbol{x}_{i} \in B
\end{aligned}
$$

Untuk suatu titik $\boldsymbol{x}_{0}$ yang diberikan, jarak hyperplane ke titik tersebut diberikan oleh

$$
J=\frac{\left|\boldsymbol{w}^{T} \boldsymbol{x}_{0}+b\right|}{\|\boldsymbol{w}\|_{2}}
$$

Jarak hyperplane ke titik terdekat dari kedua kelas disebut margin. Pencarian hyperplane classifier dilakukan dengan langkah-langkah berikut.

Andaikan $\boldsymbol{x}^{+}$dan $\boldsymbol{x}^{-}$masing-masing adalah titik pada himpunan Adan B yang terdekat ke hyperplane. Maka tanpa mengurangi keumuman, dapat ditetapkan

$$
\boldsymbol{w}^{T} \boldsymbol{x}^{+}+\boldsymbol{b}=\boldsymbol{1}
$$

dan

$$
\boldsymbol{w}^{T} \boldsymbol{x}^{-}+\boldsymbol{b}=-\boldsymbol{I}
$$

Sehingga

$$
\boldsymbol{w}^{T} \boldsymbol{x}_{\boldsymbol{i}}+\boldsymbol{b} \geq 1 \text {, untuk semua } \boldsymbol{x}_{\boldsymbol{i}} \in A
$$

dan

$$
\boldsymbol{w}^{T} \boldsymbol{x}_{\boldsymbol{i}}+\boldsymbol{b} \leq-1 \text {, untuk semua } \boldsymbol{x}_{i} \in \mathrm{B}
$$

Jarak antara hyperplane dengan titik $\boldsymbol{x}^{+}$dan $\boldsymbol{x}^{-}$dapat dituliskan menjadi

$$
J=\frac{\left|\boldsymbol{w}^{T} \boldsymbol{x}^{+}+\boldsymbol{b}\right|}{\|\boldsymbol{w}\|_{2}}=\frac{\left|\boldsymbol{w}^{T} \boldsymbol{x}^{-}+\boldsymbol{b}\right|}{\|\boldsymbol{w}\|_{2}}=\frac{1}{\|\boldsymbol{w}\|_{2}}=\frac{1}{\langle\boldsymbol{w}, \boldsymbol{w}\rangle^{1 / 2}}
$$

Definisikan

$$
y_{i}=h\left(\boldsymbol{x}_{i}\right)=\left\{\begin{array}{c}
1, \text { untuk } \boldsymbol{x}_{i} \in A \\
-1, \text { untuk } \boldsymbol{x}_{i} \in B
\end{array}\right.
$$

Maka $\left(\boldsymbol{w}^{T} \boldsymbol{x}_{i}+b\right) y_{i} \geq 1, \mathrm{i}=1,2, \ldots, \mathrm{N}$

Koefisien hyperplane classifier diperoleh dari solusi yang masalah optimasi berkendala 


$$
\underset{w, b}{\operatorname{Maks}} \frac{1}{\langle\boldsymbol{w}, \boldsymbol{w}\rangle^{1 / 2}}
$$

s.t.

$$
\left(\boldsymbol{w}^{T} \boldsymbol{x}_{i}+b\right) y_{i} \geq 1, \text { untuk } i=1,2, \ldots, N
$$

Persamaan ini ekivalen dengan solusi masalah optimasi

$$
\begin{aligned}
& \underset{\boldsymbol{w}, b}{\operatorname{Min}} \frac{1}{2} \boldsymbol{w}^{T} \boldsymbol{w} \\
& \text { s.t. } \\
& \left(\boldsymbol{w}^{T} \boldsymbol{x}_{i}+b\right) y_{i} \geq 1, \text { untuk } i=1,2, \ldots, N
\end{aligned}
$$

Dengan pendekatan metode pengali Lagrange, solusi masalah optimasi berkendala (12) dicari dari solusi masalah dual

$$
\begin{aligned}
& \underset{\alpha}{\operatorname{Maks}} \sum_{i=1}^{N} \alpha_{i}-\frac{1}{2} \sum_{i=1}^{N} \sum_{j=1}^{N} y_{i} y_{j} \alpha_{i} \alpha_{j} \boldsymbol{x}_{i}^{T} \boldsymbol{x}_{j} \\
& \text { s.t. } \\
& \sum_{i=1}^{N} \alpha_{i} y_{i}=0, \quad \alpha_{i} \geq 0, i=1,2, \ldots, N
\end{aligned}
$$

Cara diatas dapat diperluas untuk klasifikasi multikelas dengan cara membandingkan 1 kelas dengan kelas sisanya yang lain [4].

Langkah-langkah prediksi trend harga close saham dengan SVM adalah sebagai berikut:

1. Klasifikasikan nilai close harga saham LQ45 periode 4 Maret 2013 sampai 27 Januari 2014 menjadi "naik" dan "turun"dengan mencari selisih harga close hari ini dengan harga close hari kemarin. Diperoleh data sebanyak 210 data, dibagi menjadi data training sebanyak 120 buah dan 90 sebagai data testing.

2. Atribut yang digunakan adalah teknikal indikator berikut:

Stokastik \%K: $\frac{C_{t}-L L_{n}}{H H_{n}-L L_{n}}$, stokastik \%D: $\frac{\sum_{i=0}^{n-1} \% C_{t-i}}{n}$, momentum: $C_{t}-C_{t-4}$, Rate of Change: $\frac{C_{t}}{C_{t-n}} \times 100$, William's \%R: $\frac{H_{n}-C_{t}}{H_{n}-L_{n}} \times 100$, A/D Oscillator: $\frac{H_{t}-C_{t-1}}{H_{t}-L_{t}} \times 100$, Disparity $5: \frac{C_{t}}{M A_{5}} \times 100$, dan Moving Average: $\frac{\sum_{i=1}^{n} C_{t-i}}{n}$.

3. Gunakan data training untuk mendapatkan hyperplane terbaik.

4. Klasifikasikan data uji dengan menggunakan hyperplane tersebut

5. Bandingkan dengan data sebenarnya, diperoleh akurasi $55,56 \%$,

\section{Simpulan}

Dalam memprediksi trend pergerakan harga saham Indeks LQ45, metoda HMM memiliki akurasi 50,98\% sedangkan metoda SVM memiliki akurasi 55,56\%. Untuk lebih akurat, selain menggunakan data histori (teknikal indikator), disarankan juga menggunakan informasi-informasi yang beredar tentang perusahaan dan juga faktor makro ekonomi.

\section{DaftarPustaka}

[1] Baresa, Suzana, Bogdan S, Ivanovic Z., 2013., Strategy of Stock Valuation by Fundamental Analysis, UTMS Journal of Economics 4(1), pp. 45-51. 
[2] Cristianini, N. and Taylor,JS., 2000 An Introduction to Support Vector Machines and other Kernel-based Learning Methods, Cambridge University Press.

[3] Hasan, Rafiul and Nath, Baikunth, 2005., Stock Market Forecasting Using Hidden Markov Model: A New Approach: IEEE Computer Society.

[4] Jondri, Rizal.A, dan Saepudin.D., 2011., Deteksi Kelainan Paru-paru Menggunakan Wafelet dan Support Vector Machine, Prosiding Seminar Nasional Matematika 2011, Unand, Padang.

[5] Rabiner, L.R., 1989., A Tutorial on Hidden Markov Models and Select Applications in Speech Recognition, Proceedings of IEEE, vol 77., No. 2.,pp 257-286.

[6] Venkates,CK., T Yagi M, Ganesh, 2012., Fundamental Analysis and Stock Returns: An Indian Evidence, Global Advanced Research Journal of economics, Accounting and Finance Vol. 1(2), pp. 033-039. 